\title{
Implicit options in life insurance: An overview
}

\author{
Nadine Gatzert
}

Published online: 22 January 2009

(C) Springer-Verlag 2009

\begin{abstract}
Proper pricing and risk assessment of implicit options in life insurance contracts has gained substantial attention in recent years, which is reflected in a growing literature in this field. In this article, we first present the different contract designs in Europe and the United States and point out differences in the contract design. Second, a comprehensive overview and description of implicit options contained in these contracts is provided. With focus on participating contracts, we present contract design, valuation methods, and main results of several recent articles in this field. The study indicates that current developments regarding regulation (Solvency II, Swiss Solvency Test), accounting (IFRS), customer needs, and secondary life insurance markets may lead to a trend away from traditional contract design of participating policies and toward new products that are of a more transparent modular form such as variable annuities. These new contracts will contain fewer basic guarantees and a set of additional, adequately priced options.
\end{abstract}

Zusammenfassung Die adäquate Bewertung und Risikomessung von impliziten Optionen haben in den letzten Jahren stark an Bedeutung gewonnen. Ziel des vorliegenden Beitrags ist zunächst die Darstellung von Lebensversicherungsverträgen in Europa und den USA sowie das Aufzeigen von zentralen Unterschieden. Darüber hinaus werden ein umfassender Überblick und eine Beschreibung von impliziten Optionen gegeben, die in diesen Verträgen enthalten sind. Des Weiteren werden Vertragsdesign, Bewertungsmethoden und zentrale Ergebnisse von mehreren Artikeln

\footnotetext{
N. Gatzert (®)

Universität St. Gallen, Institut für Versicherungswirtschaft,

Kirchlistrasse 2, 9010 St. Gallen, Switzerland

E-Mail: nadine.gatzert@unisg.ch

Tel.: +41-71-2434012

Fax: +41-71-2434040
} 
vorgestellt, die sich mit traditionellen gemischten Kapitallebensversicherungsverträgen befassen. Die Untersuchung zeigt, dass die Entwicklungen im Hinblick auf Regulierung (Solvency II, Swiss Solvency Test), Aufsicht (IFRS), Kundenbedürfnisse und dem Zweitmarkt für Lebensversicherungen zu einem Trend weg von traditionellen Lebensversicherungsverträgen und hin zu modularen Produkten führen. Diese haben ein transparenteres Design mit wenigen Basisgarantien und einer Auswahl an zusätzlichen, adäquat bewerteten Optionen und Garantiebausteinen.

\section{Introduction}

Implicit options are a key feature in the design of life insurance products. This involves guaranteed components as well as rights to modify contract conditions during the contract term. In the past, insurers and regulators paid little attention to implicit options and guarantees in life insurance contracts. The potential threat of mispricing, insufficient risk management, and inappropriate accounting systems to the financial stability of insurers became of true concern for instance when British Equitable Life had to close to new business in 2000. ${ }^{1}$ This incident and others, such as the default of the German life insurer Mannheimer Leben in 2003, led to proper pricing and reserving for life insurance liabilities becoming an essential topic in financial regulation, international accounting standards, and the academic literature in this field.

In recent regulatory processes (e.g., Solvency II, ${ }^{2}$ Swiss Solvency Test, International Financial Reporting Standards ${ }^{3}$ ), financial reporting now requires determination of the market value of liabilities, and thus the reporting of implicit options at fair value. ${ }^{4}$ In this context, implicit options can become quite expensive in terms of capital requirements. Overall, the increasing application of the fair value approach and the recognition of implicit options will have an impact on the design of life insurance contracts, especially for traditional products. This development will be particularly visible in Europe where Solvency II in the European Union (effective after 2012) and the Swiss Solvency Test (effective January 2006) will require major changes in the capital standards for insurance companies and will insurers to properly assess the risks in their portfolios (see, e. g., Baur and Enz 2006).

The purpose of this article is to give an overview of implicit options in different markets and to discuss changes due to trends that will affect the use of these options in life policies. Toward this aim, we outline and compare the most common contract types in two largest insurance markets - Europe and the United States ${ }^{5}$ - and provide a description of options embedded in these contracts. Among these are several vital basic options that have been analyzed previously, as well as some options that have

\footnotetext{
${ }^{1}$ The case of Equitable Life is discussed in O'Brien (2006).

${ }^{2}$ For an overview and analysis of the Solvency II process, see Eling et al. (2007).

${ }^{3}$ Developments in the field of International Financial Reporting Standards and the fair valuation approach are discussed in Jørgensen (2004).

${ }^{4}$ Paragraph 5 of SFAS 157 defines the fair value as "the price that would be received to sell an asset or paid to transfer a liability in an orderly transaction between market participants at the measurement date." In IFRS, fair value is generally defined as "the amount for which an asset could be exchanged, or a liability settled, between knowledgeable, willing parties in an arm's length transaction" (IASB 2006).

${ }^{5}$ In 2005, the European share of worldwide life insurance premiums amounted to $37.6 \%$, and the United States had a 26.2\% share (Enz 2006).
} 
not been the subject of any research to date. However, fair valuation of insurance liabilities requires an appropriate financial valuation model. Hence, for the fundamental basic options previously studied in the literature, we present some selected contract designs and valuation techniques examined in several articles. We conclude our study with a discussion of product designs that will likely emerge in the future due to the major trends and developments in the life insurance industry, including regulation (Solvency II, Swiss Solvency Test), accounting (IFRS), changing customer needs, and the development of the secondary market for life insurance.

The remainder of the paper is organized as follows. Section 2 contains a comparison and description of the most common types of life insurance products in Europe and the United States. In Sect. 3, the options embedded in these contracts are described and listed in detail. A literature review on central basic implicit options is given in Sect. 4, particularly focusing on participating endowment contracts. Section 5 concludes with an outlook on expected changes in life insurance contract design.

\section{Life insurance contracts in the United States and Europe}

This section gives an overview and short description of the most popular forms of life insurance contracts in the two large life insurance markets Europe and the United States. Other policies often represent a combination or variation of these main types. The focus will be on individual insurance contracts, which are underwritten for individual protection - credit insurance, group insurance, and annuities are not considered. An overview is given in Table 1 and is based on data found in the American Council of Life Insurers' (2007) 2007 Life Insurers Fact Book and from the European Insurance and Reinsurance Federation CEA (2006). ${ }^{6}$

Table 1 Main individual life insurance policies sold in Europe and the United States

\begin{tabular}{ll}
\hline & Individual life insurance policies \\
\hline \multirow{2}{*}{ Europe } & Term \\
& Endowment \\
& Unit-linked \\
United States & Term \\
& Whole life \\
& Universal life \\
\hline
\end{tabular}

\subsection{Europe}

The most common contract types in Europe are term, endowment, and unit-linked policies. Term insurance only features death benefits for a fixed period and usually

${ }^{6}$ For the following description of life insurance policies, see Bowers et al. (1997) and Trieschmann et al. (2005). 
does not include a savings component. If the insured person dies during the policy period, the designated beneficiary receives the policy's face amount. The exact form of the term insurance depends on the contract duration, time of coverage, guarantees regarding coverage options, and changes in the amount of protection during the period the policy is in force. A policy with a constant face amount over time is called "level term" insurance; other types of term insurance include "decreasing" and "increasing" with declining (e.g., to pay off mortgages) and increasing face values.

Endowment policies provide a guaranteed death and survival benefit during a fixed contract period. In contrast to term insurance, endowment policies also have a savings element, with a benefit to be paid if the insured survives until contract maturity. The savings element is created through the so called policy reserve and is called "cash value" in the United States. When a premium is paid, mortality expenses and costs are subtracted and the remainder is invested to earn interest. Policy reserves, or cash value, thus consist of the accumulated excess premiums. Pure endowment policies pay only in case of survival and have no death benefit feature.

Endowment contracts place more emphasis on the savings part rather than on death benefits. The contract type can be participating or nonparticipating. In addition to a minimum interest rate guarantee, the contracts often feature participation in the return generated by the insurer's investment portfolio; however, dividends are not guaranteed. The amount of surplus or "bonus" credited to the policyholder's reserve depends on development of the insurer's investment portfolio and on the specific type of smoothing mechanism employed. The investment decision is made by the insurer. In the United Kingdom, these participating policies are called "with-profit" contracts ${ }^{7}$ and have much lower minimum interest rate guarantees compared to similar contracts in continental Europe. Instead, they provide higher annual bonuses (Helfenstein and Barnshaw 2003). Both term and traditional whole life insurance contracts can be purchased on a participating or nonparticipating basis.

In the case of participating policies, death benefits often consist of a guaranteed amount and accumulated interest from participation in the insurer's investment returns. The survival benefit can be increased by terminal bonus participation, depending on the insurer's investment performance. In recent years, adverse tax treatment in some countries has made endowment contracts less attractive. For example, current tax legislation in Germany reduced tax facilitation for endowment contracts, which is partly responsible for the observed trend away from traditional life insurance products and toward annuities. ${ }^{8}$

Unit-linked insurance contracts ${ }^{9}$ were introduced in the 1990 s and have attained a rapidly growing market share, especially in the United Kingdom, the biggest European life insurance market. ${ }^{10}$ After the strong decline in life insurance demand due

\footnotetext{
${ }^{7}$ A comparison of different smoothing schemes in the United Kingdom can be found in Haberman et al. (2003).

${ }^{8}$ See Enz (2006, p. 17) for a description of the development of unit-linked products.

${ }^{9}$ An extensive discussion of unit-linked insurance products is provided in Helfenstein and Barnshaw (2003).

${ }^{10}$ The four biggest life insurance markets in Europe together represented $70.9 \%$ of the total European life insurance premiums in 2004: United Kingdom (27.5\%), France (19.1\%), Germany (12.4\%), and Italy (11.9\%) (see European Insurance and Reinsurance Federation CEA 2006, p. 12). According to the Euro-
} 
to the stock market crisis of 2001, the upturn in the European stock markets led to a growth in the European life insurance market in 2005. Unit-linked products benefited from this development, especially in Belgium, Germany, France, and Portugal. ${ }^{11}$

In contrast to participating life insurance contracts, the investment risk of unitlinked contracts is entirely borne by the policyholders: the policyholder decides how to invest his or her premium, choosing from among several asset categories. There are several variations of unit-linked insurance policies: the savings part can be linked to units of a mutual fund or it can be index-linked to some index such as a bond index, equity index, or another reference index. Alternatively, the contract can be a guaranteed equity-linked policy, which guarantees a minimum return on premiums paid.

Unit-linked policies also feature a guaranteed death benefit, which is the greater of a fixed guaranteed amount or the value of the accumulated funds. Alternatively, some contracts promise the value of the accumulated funds in addition to a minimum guaranteed death benefit. In case of survival until maturity, the value of the accumulated funds is paid.

\subsection{United States}

In the United States, three most common policies sold are term, whole life, and universal life insurance policies (American Council of Life Insurers 2007; Trieschmann et al. 2005). Sales of endowment policies are negligible. In contrast to term insurance, whole life insurance contracts remain in force for the insured's entire lifetime, a type of contract rarely found in Europe. The contracts offer fixed premiums, have guaranteed death benefit, and feature a savings element. Early termination of the policy (i. e., before death) requires a transfer of the cash value (less a surrender fee) to the insured, which is guaranteed by the so-called nonforfeiture option. The nonforfeiture option is obligatory for all policies with cash value and states that the policy reserve belongs to the policyholder and cannot be lost as a result of premature termination of premium payments. There are three methods of transferring the cash value to the policyholder. In the case of the paid-up insurance, the policyholder stops premium payments and the policy continues with reduced benefits that are determined according to the cash value present at the exercise date. Alternatively, the policyholder can choose a lump sum paid in cash (for surrender, "cash value option") or to use the cash value to buy extended-term insurance. The nonforfeiture benefits for all three methods must be appropriately comparable in their actuarial value (Trieschmann et al. 2005, p. 334).

Universal life insurance contracts, a highly flexible product, were first introduced in 1979. They allow flexible premium payments - the policyholder decides on the timing and size of subsequent premiums. Moreover, the size of the death benefit can be adjusted. Some insurers may require a proof of insurability if a request is made to increase the death benefit. In contrast to whole life insurance policies, the cash value of universal life insurance contracts varies, depending on the insurer's investment re-

pean Insurance and Reinsurance Federation CEA (2006, p. 10), the share of unit-linked products in total life insurance premiums in the United Kingdom increased from $70 \%$ to $78 \%$ in 2004.

${ }^{11}$ See Enz (2006, p. 17). 
sult, mortality experience, expenses, and the amount and timing of premiums paid by the policyholder. If the mortality and expense charges exceed the cash value amount at any time, the policyholder either must make up the deficit or decrease the death benefit or the policy will lapse. Both universal and whole life insurance contracts can be offered on a participating or nonparticipating basis.

\section{Implicit options in life insurance}

The common types of life insurance products discussed in the previous section are usually replete with implicit options. Implicit options provide the right to modify contract conditions during the contract term. Exercising the options can affect the size and timing of the policy's cash flows and thus imply a substantial value for the policyholder. The exact form and design of specific options may vary across different countries. This section provides a comprehensive overview and description of implicit options. Among the options looked at are fundamental basic options that have been previously studied in the literature, where it was shown that these options have the potential of a substantial financial risk. Often, these options are required by law (e.g., surrender option or paid-up option). We also take a look at several special options that have not been extensively studied in the literature to date. Table 2 contains a comprehensive list of implicit options. For descriptions of the options, see also, e. g., Dillmann (2002), Herr (2004), and Trieschmann et al. (2005).

\subsection{Dividend options}

Dividend payments are a feature of participating policies and are based on the insurer's investment, mortality, and expense results. Dividends can be paid to the policyholder in cash, used to reduce future premiums, used to buy additional amounts of either paid-up cash value coverage or one-year term insurance, or can be accumulated with interest by the insurer. The last case can represent substantial risk to the insurer if the contract contains a minimum fixed interest rate to be applied to the accumulated dividends.

Policyholders can either participate directly in the surplus or according to a smoothing scheme based on book values. One valuable annual surplus distribution mechanism is the "year-to-year" or "cliquet-style" guarantee. ${ }^{12}$ In this case, policy reserves annually earn the greater of a minimum interest rate guarantee or a fraction of the surplus generated by the insurer's investment portfolio. The way surplus is determined differs and might employ a smoothing mechanism. A comparison of interest rate guarantees and different surplus distribution schemes for several countries can be found in Cummins et al. (2004). Once the surplus is credited to the policy reserve, it becomes part of the guarantee and thus increases the guaranteed maturity payment. Contracts that provide only a maturity guarantee without participation over time are sometimes referred to as having a "point-to-point" guarantee. Usually, these

\footnotetext{
${ }^{12}$ See, e. g., Grosen and Jørgensen (2000). 
Table 2 Overview of implicit options in life insurance

- Dividend options

- Accumulation at interest with minimum interest rate guarantee

- Cash

- Premium payment reduction

- Paid-up additions

- One-year term option

- Change of dividend distribution mechanism

- Premium payment options

- Paid-up option

- Resumption option

- Flexible premium payments

- Dynamic premium increase

- Surrender option

- Flexible expiration option

- Settlement options

- Lump-sum option

- Life income option/guaranteed annuity option

- Fixed-period option

- Fixed-amount option

- Interest option

- Right of objection

- Contract cancellation

- Dynamic/increasing premiums

- Policy loan

- Policy backdating

- Conversion option

- Extended-term insurance

- Lump-sum settlement option during annuity

- Additional payments

- Increase death benefit

- Shorten contract duration

- Reinstatement

- Coverage extension option

- Cost-of-living rider/inflation option

- Guaranteed insurability rider

- Waiver of premium benefit

- Accelerated death benefits

- Accidental death benefit

- Contract term extension option

guarantees offer some terminal bonus payment if the insurer's investment portfolio has performed sufficiently well. ${ }^{13}$

Instead of accumulating dividends so as to earn interest, the policyholder can have the dividends paid in cash or use them to reduce premiums (premium payment re-

\footnotetext{
${ }^{13}$ See, e. g., Briys and de Varenne (1997); Grosen and Jørgensen (2002).
} 
duction). In case of the paid-up additions options, dividends are used to increase benefits and coverage without the policyholder having to undergo an additional medical examination or expenses. The additional insurance consists of a higher death benefit and cash value. Alternatively, dividends can be applied to purchase as much additional one-year term insurance as possible without increasing the premium payment. Due to adverse selection, many insurers require that this dividend option must be chosen at inception of the contract. Otherwise, the insurer can insist on an additional medical exam to prove insurability if policyholders ask for this option during the contract term. Furthermore, the policyholder may have the right to choose a different dividend distribution mechanism ("change of dividend distribution mechanism").

\subsection{Premium payment options}

Most life insurance contracts contain premium payment options. ${ }^{14}$ Universal life policies, for instance, allow policyholders to choose the timing and size of premium payments - to a certain degree and as long as there are sufficient policy reserves - which is known as a flexible premium payments option. Even though not all contract types are as flexible as universal life policies, in most European countries and across the entire United States, the right to stop premium payments (paid-up option) is an option required by law. In the United States, this right is a consequence of the nonforfeiture options that are obligatory for all contracts with cash value.

When exercising the paid-up option, the contract is not terminated but continues in force with reduced benefits. The amount of insurance benefit therefore depends on the policy reserve present at the exercise date, which is used as a single premium to buy the same type of insurance as the original contract, for example, endowment or whole life. Usually, a surrender fee is subtracted from the reserves. The right is a put option on a forward contract where the policyholder has committed to buy bonds with annual premiums having a strike price of zero. This means that the effect of the option is to exchange the original contract for a new contract with reduced benefits and no premium payments.

In addition to the paid-up option, contracts can contain the right to resume premium payments later, thus increasing the previously reduced benefits (resumption option). To regain the original insurance benefit (i. e., benefits in place prior to making the contract paid-up), the policyholder either can pay the premiums in arrears or increase the original premium size. Alternatively, the original premium size can be retained without paying back outstanding premiums, which will lead to lower benefits than in the original contract. In some contracts, the resumption option can be restricted to a certain time period after making the contract paid-up. If the policyholder has made the contract paid-up due to, for example, high capital market interest rates, the option to resume and repay the premiums offers an opportunity to receive the higher guaranteed interest rates in the contract, which is a call on a forward contract (where the policyholder has committed to buy bonds with annual premiums), with the strike price being the repayment of premiums. Another type of premium

\footnotetext{
${ }^{14}$ See, e. g., Steffensen (2002); Linnemann (2003, 2004); Gatzert and Schmeiser (2008). 
payment option is the dynamic premium increase, where premiums are increased by a fixed percentage annually, for example.

\subsection{Surrender option}

In contrast to the paid-up option, the surrender option ${ }^{15}$ terminates the contract and the policyholder receives the surrender value - consisting of the policy reserve less a surrender fee - as a lump sum in cash. In the case of unit-linked policies, the surrender benefit is the value of the accumulated funds less a surrender fee. The policy reserve also contains dividends. Since the surrender option can be used at discrete exercise dates, it can be classified as a Bermudan put option on the cash flow stream of future expected insurance benefits with a strike price amounting to the surrender value. There is financial risk inherent in the surrender option due to the possibility of many policyholders with high surrender values exercising the option at a time when interest rates are rising. In addition, the surrender option bears insurance risk in the sense of adverse selection if it occurs that the mostly "good risks" surrender the contract, leading to a worsening of the risk situation in the insurer's portfolio. ${ }^{16}$

\subsection{Flexible expiration option}

Endowment contracts can include the flexible expiration option, ${ }^{17}$ which gives the policyholder an annual opportunity to terminate the contract prior to regular expiration and to receive the accumulated policy reserves, including guarantees and surplus participation, without paying a surrender fee. The option can be exercised after the policy reserve has exceeded the guaranteed survival benefit for the first time or during the last five to ten years of the policy, as is studied by Dillmann and Ruß (2001). The later the exercise date, the larger the benefit paid to the policyholder. From a financial viewpoint, this option corresponds to a Bermudan put on a coupon bond with a strike price equal to the lump-sum benefit. The coupon bond is the remaining cash flow of the policy terminated by the policyholder with expected death benefits less expected premium payments (in case of periodic premium payments) as coupons and expected survival benefit as face value. The option is Bermudan since it can be exercised annually on the policy's anniversary date. An advantage for the insured is that the interest rates earned by the policy typically come from long-term investments, which is in contrast to the possibility to annually surrender the policy without surrender charges, actually implying a short-term investment.

\subsection{Settlement options}

Policyholders can choose among different settlement options for how death or survival benefits will be paid. The most common way to settle a policy is to pay the insurance benefits in a lump sum and to thus terminate the policy, which leaves the

\footnotetext{
${ }^{15}$ See Albizzati and Geman (1994); Bacinello (2001, 2003a, 2003b); Grosen and Jørgensen (1997, 2000); Steffensen (2002).

${ }^{16}$ See Gatzert et al. (2008).

${ }^{17}$ See Dillmann and Ruß (2001).
} 
insurance company without further obligation. Life income options ${ }^{18}$ guarantee the beneficiary an annuity for the remaining lifetime. There are several variations of this type of option. For instance, guaranteed annuity options were commonly offered in U.S. tax-sheltered insurance products and in U.K. retirement savings contracts during the 1970 s and 1980s. ${ }^{19}$ At maturity of the contract, the accumulated policy reserve is converted to a life annuity at a fixed guaranteed rate, which corresponds to a call option on a coupon bond. The financial risk associated with this option arises due to demographic factors (longevity), market conditions at the exercise date (long-term interest rates and equity performance), and the size of the annuity. When long-term interest rates began to fall in the 1990s, the value of guaranteed annuity options increased substantially. This type of option became of special concern when British Equitable Life had to close to new business due to an insufficient pricing and reserving of the time value of guaranteed annuities, among other reasons. ${ }^{20}$

As an alternative to a lump-sum settlement, the insurance benefits can be paid to the beneficiary during a fixed period in equal installments (fixed-period option). The size of the payments depends on the frequency, on the length of the payment period, and on the interest paid by the insurer on the policy reserve that has not been paid out. Often, a minimum payment is guaranteed. If interest earned is above the guaranteed rate, the insurer will credit the excess interest to the installment and thus increase its size. In general, the beneficiary retains the option to withdraw the present value of future cash flows after having exercised the fixed-period option (lump-sum settlement option).

Instead of fixing the period, one can fix the size of installments under the fixedamount option. Size and frequency of payments then determine the initial length of the payment period, which can be increased if interest is earned in excess of the guaranteed rate. The policyholder can also decide to take the interest option, in which case the insurer keeps the insurance benefits and pays interest to the beneficiary, usually involving at least a guaranteed interest rate. As under the fixed-period option, the beneficiary can generally withdraw a part or the entire amount subject to certain restrictions.

\subsection{Right of objection}

Usually, the policyholder has the right to object and cancel a contract within a fixed period after inception of the contract without incurring financial consequences. If the policyholder does so, all premiums paid must be refunded. This can result in a financial risk for the insurance company if premiums have immediately been invested in the market, as the liquidation can lead to a loss in interest. This is of particular concern in the case of unit-linked life insurance contracts where liquidation of refundable premiums can represent a substantial risk.

\footnotetext{
${ }^{18}$ See Milevsky and Promislow (2001); Boyle and Hardy (2003); Haberman and Ballotta (2003).

${ }^{19}$ Participating endowment contracts made up approximately $80 \%$ of the total liabilities for contracts with guaranteed annuity options (Boyle and Hardy 2003). The remaining part was mainly composed of unitlinked contracts.

${ }^{20}$ See O'Brien (2006). 
Furthermore, policyholders can object to the dynamic increase in premiums. Some insurers allow only two objections before annulling the right of objection. This option represents only a low financial risk for the insurer.

\subsection{Policy loan}

Policyholders can borrow part of the cash value from the insurer during the period of insurance coverage. If the borrowing interest rate charged by the insurer is close to the market interest rate, the financial risk for the company is limited, but can be substantial if the interest rate was fixed at inception of the contract. When the policyholder dies, total outstanding loans and accumulated interest are subtracted from the policy reserves before benefits are paid. To avoid a lapse of the policy, interest must be paid by the policyholder if the sum of the loan plus interest drops below the cash value. Many insurers offer an automatic premium loan provision to ensure that the policy continues, which becomes effective when premiums remain unpaid. Outstanding premiums are taken from the cash value and treated like a loan against the policy.

\subsection{Policy backdating}

The practice of policy backdating ${ }^{21}$ is very common in insurance business. Insurance contracts can be backdated so that the date of the policy is earlier than the actual application date, usually by as much as six months. For example, age nearest birthday is used for premium calculations and thus premiums are reduced due to the lower age used for calculations. However, policyholders have to pay premiums in arrears for the backdated period. Hence, the option is of value if the reduction of premiums more than compensates for the premiums that have to be paid for the backdated interval.

\subsection{Conversion option}

The conversion option is often offered in the context of term insurance contracts and allows converting a term insurance policy into an endowment insurance or annuity policy; without the policyholder having to undergo further proof of insurability. In general, to avoid adverse selection, the insurer limits the period of time within which this option can be exercised.

\subsection{Extended-term insurance}

Extended-term insurance is part of the nonforfeiture option and can also take effect if premiums remain unpaid after the grace period and the policyholder does not use one of the other nonforfeiture options (paid-up insurance or cash value option). In this case, the insurer uses the policy reserve to calculate the contract duration of a term insurance contract having the same death benefit as provided in the original contract. Since the choice between paid-up insurance and extended-term insurance

\footnotetext{
${ }^{21}$ Carson 1994; Carson and Ostaszewski 2004.
} 
can implicitly deliver information on the health status of the insured, some insurers use different life tables to calculate benefits for paid-up insurance and extended-term insurance contracts in order to account for possible adverse selection.

\subsection{Lump-sum settlement option during annuity}

The lump-sum settlement option gives the beneficiary the right to withdraw expected future annuity payments, discounted with the technical rate, as a lump-sum settlement prior to the contract's regular expiration date, for example under the fixed-period option and the interest option.

\subsection{Additional payments}

By making additional payments, policyholders can increase the coverage of the insurance contract. The additional payment corresponds to a single premium for a new contract without acquisition charges. Alternatively, additional contributions can be used to shorten the duration of endowment contracts by increasing the mathematical policy reserve. The adjusted remaining contract term is then determined via actuarial principles. In this case, additional contributions do not increase the death benefit, but do result in a higher savings value (cash value). Additional payments are often restricted to a fixed percentage of the sum insured, must exceed a minimum amount, and are allowed to be exercised only after the contract has been in effect for a certain duration. This option can be profitable for the policyholder if policy dividends are higher than alternative market interest rates, which represents a call on a bond.

\subsection{Reinstatement}

Policies that have lapsed, for example, due to nonpayment of premiums, can be reinstated within a fixed time period. In the United States, a grace period clause usually gives the insured an extra 30 days to pay the outstanding premiums before the policy actually lapses. Alternatively, an automatic premium loan provision can prevent policy lapses as long as sufficient cash values exist to cover premiums. Once the policy has lapsed or has been surrendered, it may be reinstated within a certain period after lapse (in the United States this is usually three to five years), given evidence of insurability. The premiums in arrears during the period of lapse must be paid. The option to reinstate a contract instead of buying a new one can be valuable for the policyholder if the old contract conditions are more favorable, for example, with respect to implicit options, than the new ones would be.

\subsection{Coverage extension option}

There are several options that can affect the amount or character of the coverage in a life insurance contract. To increase the amount of coverage, policyholders can either choose the cost-of-living rider or the guaranteed insurability rider, which allows a change in the insurance coverage without proof of insurability. If the cost-of-living 
rider is chosen, the death benefit is automatically increased by the same percentage that the consumer price index has increased since inception of the contract. The policyholder pays accordingly for this additional coverage. In the United Kingdom, this option is also called the "inflation option." If the cost-of-living rider is initially refused, but the policyholder later requests it, insurability must be proven. The guaranteed insurability rider gives policyholders the right to increase the face amount of the policy under certain circumstances, for example, marriage or birth of a child.

The waiver of premium benefit exempts policyholders from paying premiums in case of disability before a specific age, such as age 60 or 65 . This option is not expensive and ensures that the policy continues with the same benefits, regardless of the policyholder's health. Some insurance contracts may require a waiting period before waiving the premiums. The accelerated death benefit is also called a "living benefit option" and it pays a discounted percentage of the policy's face value before the event of death under specified circumstances. Some insurers consider the exercise of this option as a termination of the contract; others pay the remaining benefit to the beneficiary in case of the insured's death. The death benefit can be increased in the case of accidental death by paying a small surcharge (accidental death benefit). In this case, the beneficiary receives, in addition to the death benefit in the basic contract, an extra amount, which is often the face value of the policy. Insurers usually exclude certain situations from the application. Usual exclusions are, for example, death from suicide, illness, war, or when death occurs more than 120 days after the event of an accident.

\subsection{Contract term extension option}

Some insurance contracts offer an option to extend the contract term for a specific time span while keeping the contract conditions. The option can be exercised until maturity and is granted given that the insured's health status has not worsened. There might be other restrictions concerning the total contract term and the insured's age at the new maturity date. This option can be valuable if policyholders can keep high guaranteed policy interest rates when market interest rates are low.

In general, all contract types outlined in Table 1 feature fundamental basic options such as paid-up and surrender options. In the case of term insurance, typical extra options are the conversion option, the option to make additional payments to adjust the death coverage, and contract term extension. Endowment contracts often offer coverage extension options for death benefits, dynamic premium increase, and additional payments. Unit-linked contracts generally include options similar to those offered in traditional endowment contracts. However, the right of contract cancellation within a certain time period can imply financial risk (cf. previous discussion in this subsection). Further options frequently offered with this type of insurance are the contract term extension and policy loan. As in the case of term insurance, the conversion option allows the policyholder to convert the unit-linked insurance policy into an endowment contract with the same premium level and maturity date, while death and survival benefits are adjusted accordingly. The value of the reference portfolio at the exercise date is used to calculate the adjusted benefits. Whole life contracts also feature coverage extension options, policy loan, paid-up additions, and extended-term 
insurance. Universal life is the most flexible contract type with respect to premium payments, which are flexible in timing and size. Other options frequently available in a universal life insurance contract are similar to those offered in a whole life contract.

\section{The impact of implicit options: The case of participating endowment policies}

This section presents selected work that has been done in the field of implicit options. The focus is on fundamental options in traditional participating endowment contracts. The purpose of this study is to describe, in more detail, the contract design, valuation techniques, and main results of selected papers so as to illustrate the impact of embedded options in traditional life policies and the calculation of fair value.

One common way to price insurance contracts at fair value is to use contingent claims pricing theory as developed and applied by Black and Scholes (1973) and Merton (1973). The particular adequacy of arbitrage models has been discussed by Babbel and Merrill (1998), who provide a discussion of economic valuation models for insurers. The application of contingent claims theory to pricing unit-linked life insurance contracts was pioneered by Brennan and Schwartz (1976) and Boyle and Schwartz (1977).

In the following description, emphasis is placed on papers that analyze participating endowment policies with implicit options. These contracts and options have been studied amongst others by Bacinello (2003a, 2003b), Ballotta et al. (2006), Briys and de Varenne (1997), Dillmann and Ruß (2001), Gatzert and Kling (2007), Gatzert and Schmeiser (2008), Grosen and Jørgensen (2000, 2002), Guillén et al. (2006), Haberman and Ballotta (2003), Hansen and Miltersen (2002), Jensen et al. (2001), Kling et al. (2007), Linnemann (2003, 2004), Miltersen and Persson (2003), Steffensen (2002), and Tanskanen and Lukkarinen (2003).

\subsection{Dividend options with accumulation at interest}

Dividend options with minimum interest rate guarantees have been analyzed in several papers for different surplus distribution smoothing schemes, such as cliquet-style or point-to-point guarantees as are common in various countries. Policies similar to French contracts have been studied by Briys and de Varenne (1997); a common U.K. cliquet-style contract is presented in Ballotta et al. (2006); a contract design common in Denmark is set up in Hansen and Miltersen (2002); a model for German policies is developed in Kling et al. (2007); Gatzert and Kling (2007) compare different cliquet-style and point-to-point guarantees and analyze the risk associated with fair contracts. ${ }^{22}$ Moreover, in some papers, contracts with dividend options form a basis for including and analyzing additional options. ${ }^{23}$ In the following, we describe results from Grosen and Jørgensen (2002) that includes a point-to-point guarantee with a regulatory mechanism.

\footnotetext{
${ }^{22}$ An example of how minimum interest rate guarantees in participating life insurance contracts can be priced is provided in the Appendix A.

${ }^{23}$ See Grosen and Jørgensen (2000); Bacinello (2003a, 2003b); Gatzert and Schmeiser (2008). 


\subsection{Point-to-point dividends}

In the model considered by Grosen and Jørgensen (2002), policyholders (the liability holders of the company) and equityholders each make an up-front payment at inception of the contract, which sum up to the total initial assets of the company. The insurance company guarantees the policyholders a maturity payment and an optional participation in the terminal surplus, which is a fraction of the excess value of the policyholders' share in the total value of the company and the guaranteed maturity payment. The authors include a default put option in the model, i. e., equityholders have limited liability. Moreover, they incorporate a regulatory constraint for the insurer's assets. If the market value of assets falls below a certain regulatory threshold at any point in time, the company is closed down and the recovered market value is distributed to the policyholders. Risk-neutral valuation is used for pricing, where assets are assumed to follow a geometric Brownian motion and interest rates are constant. Valuation of the contracts is done analogously to financial knock-out barrier options with an exponential barrier.

To find initially "fair contracts," contract parameters are calibrated such that the present value of liabilities under the risk-neutral martingale measure is equal to the up-front premium paid by the policyholder. This requirement is consistent with a noarbitrage setting. Using the fairness condition, an inverse relation between the guaranteed interest rate and the terminal surplus participation coefficient is shown. Hence, an increasing guaranteed interest rate requires a decrease in the participation rate. Moreover, as the policyholders' participation rate in the terminal bonus tends to one, they will be the only group investing in the company while, at the same time, the initial contribution of the equityholders decreases to zero. Further, a decomposition of the contract components shows that introducing a regulatory mechanism reduces the value of the default put option.

\subsection{Surrender option}

Bacinello (2003b) analyzes a type of participating life insurance policy that is commonly sold in Italy. The single up-front premium paid by the policyholder is calculated using the equivalence principle, as is common in standard actuarial practice, given an initial guaranteed death and survival benefit. The contract contains a minimum interest rate guarantee, annual participation in the return of the insurer's investment portfolio, and a surrender option. The policy features death and survival benefits, with death and survival probabilities extracted from a mortality table. For valuation, the recursive algorithm of the Cox et al. (1979) discrete option pricing model is used with constant interest rates. The value of the contract is thereby affected by mortality and financial risk.

The benefit payable to the insured in case of death or survival is annually increased by the greater of a guaranteed interest rate or a fraction of the return of a reference portfolio. The cliquet-style surplus distribution system is equal to the compound reversionary bonus method. In contrast to Ballotta et al. (2006), mortality costs are also taken into account. The calculation of the surrender value is done in two different ways by following an "empirical" and a "traditional" rule. For the empirical rule, the 
proportionate paid-up value is discounted from maturity to the surrender date using an appropriate rate, which is generally greater than the guaranteed interest rate. The traditional way is to use a percentage of the policy reserve, which is decreasing with time to maturity. Contract parameters are calibrated such that the present value of the policy under the risk-neutral measure (the fair price) is equal to the up-front premium paid by the policyholder.

The effect of individual contract parameters is studied by decomposing the contract into its components - basic contract, participation option, nonsurrendable participating contract, surrender option, and whole contract. Bacinello (2003b) shows that the insured's initial age has only a small influence on premiums. Furthermore, the participation option appears to be very valuable, strongly influenced by the guaranteed interest rate. In contrast, the surrender option is cheap and its value decreases with increasing age since the option can be exercised only in case of survival. The value of the surrender option decreases with increasing participation rate and generally exhibits a strong sensitivity with respect to this parameter. The results for both types of surrender options (empirical and traditional) show that surrender penalties can substantially reduce the value of the surrender option.

\subsection{Premium payment options}

Steffensen (2002) treats the paid-up option in a life insurance contract and studies the impact on the insurance company's reserve situation. The author sets up a general framework for an insurance contract that includes surrender and paid-up options ("intervention options"). The reserve of the insurance contract is thereby defined as the market value of future policy cash flows. One main result of the paper is the derivation of the reserve for this contract as a solution to a generalized Thiele's differential equation, a quasi-variational inequality. This inequality can be used to determine conditions under which exercising the option will be optimal such that the option values are arbitrage-free - an approach that is based on optimal intervention strategies.

\subsection{Flexible expiration option}

The flexible expiration option in participating endowment contracts is treated in Dillmann and Ruß (2001), where the price of the option is calculated using the Hull-White model for the short rate process. The contract includes death and survival benefits that are assumed to be paid by the insurance company based on a guaranteed interest rate and constant (estimated) surplus rate. The up-front premium paid by the policyholder is calculated using the actuarial equivalence principle based on the guaranteed benefits. In their model, policyholders are allowed to exercise the flexible expiration option during the last years of the contract. Option values are derived based on the assumption that policyholders exercise the option in a rational manner.

Some of the main findings from this paper are that the option value increases for longer flexible expiration periods. The inclusion of mortality leads to the effect that the option price first increases and then decreases whenever the contract term is increased. As in the case of surrender options, the option value decreases with increas- 
ing age of the insured, since exercise is conditional on survival. Furthermore, the value increases with increasing volatility of the short rate process.

\subsection{Settlement option: Guaranteed annuity option}

Boyle and Hardy (2003) discuss the valuation and possible hedging methods for guaranteed annuity options, using the case of unit-linked insurance contracts as an example. The methods presented in the paper can also be applied to participating endowment contracts. A single up-front premium paid by the policyholder is invested in an asset account. At maturity, the policyholder has the right to choose between the accumulated value of assets (the lump sum) or the annuity payments. The policy guarantees a fixed conversion rate for calculating a guaranteed minimum annuity payment (lump sum divided by the conversion rate). Given the market price of an annuity at maturity, the value of the option can be calculated as the excess of the annuity cost over the lump sum. Thereby it can be shown that the option will not be exercised if the market price of an annuity of $\$ 1 \mathrm{p}$. a. (the current annuity factor) is less than the conversion rate (the guaranteed annuity factor). Crucial in the determination of the option value is the market price of the annuity at maturity, which depends on longterm interest rates and mortality and expense assumptions. The size of the option liability will also depend on the size of the lump-sum payment.

Within the model framework, the Hull-White model is used for the short rate process. Mortality and financial risks are assumed to be independent and mortality risk is diversifiable (using a mortality table). The price of the option is then calculated with the numeraire approach using the forward measure conditional on survival. The payoff corresponds to a call on a coupon bond, where the coupons are the respective survival probabilities. In numerical analysis, the historical time series of market values is derived. The authors further compare option values for different life tables to illustrate the effect of longevity on the option value. The results show that the mortality assumption has a substantial impact on value. In contrast, volatility appears to have only a minor effect on the option value for long periods. This is explained by the fact that, in general, the sensitivity of option values with respect to volatility is highest when the option is close to being at-the-money.

In the literature, various types of implicit options have been analyzed in different contract settings. This section illustrated the complexity of the valuation and impact analysis, due to, among other things, the interaction and counterbalancing effects of different options. Moreover, the discussion showed that the numerous implicit options contained in traditional participating life insurance contracts can be of substantial value. Further aspects having a bearing on the valuation of insurance contracts are risk measurement and the effect of management strategies.

\section{Trends and outlook}

Fair valuation and adequate pricing are increasingly applied in the insurance market, partly enforced by regulatory authorities (see, e. g., Solvency II in the European Union, Swiss Solvency Test, International Financial Reporting Standards). Important 
to this process are stochastic models and supplementary scenario tests, which generally lead to a much better assessment and awareness of risks through increased transparency. Besides accounting and regulation, customer needs are changing. In an environment of easy and fast information retrieval, customers are increasingly critical and demanding. Product design and prices are questioned, and more transparent and easy to understand products are desired by customers (Wong et al. 2007). Another major development concerns the growth of the secondary market for life insurance, which especially concerns the U.S. market (Doherty and Singer 2002), representing the largest life settlement market worldwide. In the secondary market for life insurance, policies are purchased by life settlement providers to be optionally placed in closed funds for life settlement securitization or kept in the buyer's own books. The payment to the selling policyholder is above the surrender value offered by the primary insurer. The investor continues to pay premiums until the contract matures due to death or reaching a fixed term and then receives the contract's payoff. In the U.S. senior life settlement market, specifically life insurance policies of senior citizens above age 65 with below-average life expectancy are traded. Since life settlement markets are currently comparably small compared to primary insurance markets, only a strong growth of the life settlement market will force life insurers to reconsider their risk management and policy pricing, e. g., with respect to a more rational option exercise behavior. However, these issues still need to be taken into consideration and adequate pricing becomes even more relevant. Our study in the previous sections indicates that these developments - in the long run - may result in a change of traditional product designs and a trend toward contracts priced at fair value in modular form with fewer basic guarantees and adequately priced additional options available to policyholders.

Implementation of the fair value concept in the context of a new regulatory environment may result in increased capital requirements - especially for life insurance companies - and thus to a decrease in the individual insurer's capital adequacy. ${ }^{24}$ This is also due to the fact that under the new requirements, implicit options have to be taken into account, in contrast to the previous statutory system of Solvency I. In particular, insufficient diversification and market and insurance risk may lead to a substantial increase of the target capital under the risk-based capital standards, despite the fact that - according to FitchRatings (2005) - most insurance companies already hold more capital than necessary under the (statutory) Solvency I requirements in Europe. In this context, the methods and valuation techniques described in the previous section will be of substantial relevance. Hence, even though the effect of the fair value concept might be limited on the corporate level, it likely will have consequences for product design and product lines. It will also encourage innovative product development; for example, since diversification serves to reduce target capital, new product lines might be introduced to accomplish such a reduction. The application of the fair valuation approach in line with the new standards could thus lead to a change in the life insurance landscape over the next years (Baur and Enz 2006).

\footnotetext{
${ }^{24}$ See results of the Swiss Solvency Test preliminary analysis field test conducted by the Swiss regulators in 2005 (Bundesamt für Privatversicherungen 2005).
} 
The fair value approach provides increased transparency in the sense that risks can be correctly classified through fair pricing and scenario analysis. This simplifies the identification of unprofitable product lines that have capital-intensive components. Furthermore, specific scenarios for the life insurance sector, such as lapsation, pandemic, disability, and longevity, may significantly lower the attractiveness of certain product lines. ${ }^{25}$ Particularly long-term products will become more expensive in terms of capital requirements, which will mainly affect traditional insurance policies with guarantees and options that carry substantial financial and insurance risks, as outlined in the previous sections. This situation gives rise to two consequences for the design of life insurance contracts. If insurance companies decide to continue to offer high guarantees, contracts will need to be priced at market values and the fair premiums must be invested in risk management tools like hedging or reinsurance. This way, high guarantee levels can be kept if policyholders are willing to pay adequate prices. Otherwise, contracts with fewer guarantees and higher upside potential, such as unitlinked contracts where policyholders bear the main investment risk, could be offered. Unit-linked contracts are already showing a trend toward growing market share (see Sect. 2).

Both consequences can be accommodated by the so-called modular, or building block, contract designs, which have been sold in Germany since 2005 in the form of variable annuities. These contracts provide only a basic guarantee, but additional options may be acquired separately at an adequate (fair) premium. This sort of contract design could result in a situation where only capital-intensive product components important to policyholders (who are thus willing to pay for them) are offered. Apart from this, since the risk of these policies is priced, modular products will tend to benefit from the introduction of Solvency II and the Swiss Solvency Test, as have unit-linked contracts that have policyholders bear the investment risk.

A trend toward risk management systems based on the fair value concept offers significant advantages for insurance companies. The resulting higher transparency allows correct classification of the actual risks in the portfolio, thus substantially reducing the likelihood of losses and defaults. Modular products represent an important step toward a transparent contract design that will benefit both policyholders and insurers. In particular, the risk of implicit options becomes apparent and more easily manageable.

\section{Appendix A}

A1 Modeling and pricing of a participating life insurance contract with minimum interest rate guarantee

The following example presents a modeling and pricing procedure for participating life insurance contracts. Pricing is conducted using risk-neutral valuation. ${ }^{26} \mathrm{We}$ con-

\footnotetext{
${ }^{25}$ The Swiss Solvency Test preliminary analysis field test in 2005 showed that particularly the lapsation and longevity scenarios can have substantial effects in terms of the risk-bearing capital.

${ }^{26}$ See Gatzert and Kling (2007) for a more detailed analysis of fair pricing and shortfall risk for different contract types.
} 
sider an insurance company, where policyholders make an exogenously given upfront payment of $P_{0}$ at contract inception (at time $t=0$ ), and $E_{0}$ is the initial payment made by the equityholders. The total value of initial contributions is then invested in assets.

\section{A1.1 Modeling the assets}

We assume that the total market value of the asset portfolio follows a geometric Brownian motion. ${ }^{27}$ Under the objective (real-world) measure $\mathbb{P}$, the asset process is described by

$$
d A(t)=\mu(t) A(t) d t+\sigma(t) A(t) d W^{\mathbb{P}}(t),
$$

with asset drift $\mu(t)$, volatility $\sigma(t)$ that are assumed to be constant over time and a $\mathbb{P}$-Brownian motion $W^{\mathbb{P}}$. We assume a complete, perfect, and frictionless market. Thus, the solution of the stochastic differential equation ${ }^{28}$ is given by

$$
A(t)=A(t-1) \cdot \exp \left(\mu-\frac{\sigma^{2}}{2}+\sigma \cdot\left(W^{\mathbb{P}}(t)-W^{\mathbb{P}}(t-1)\right)\right),
$$

with $A(0)=P_{0}+E_{0}$. Since pricing is conducted using risk-neutral valuation, the measure needs to be changed to the (risk-neutral) unique equivalent martingale measure $\mathbb{Q}$. In this setting, the drift of the geometric Brownian motion changes to the risk-free interest rate $r$, and development of the assets is given by

$$
d A(t)=r A(t) d t+\sigma(t) A(t) d W^{\mathbb{Q}}(t),
$$

where $W^{\mathbb{Q}}$ is a $\mathbb{Q}$-Brownian motion. The solution of this stochastic differential equation under $\mathbb{Q}$ is given analogously as under $\mathbb{P}$.

\section{A1.2 Modeling the liabilities}

Let $P$ denote the policyholder's account, i. e., the book value of the policy reserves. Every year $t=1,2, \ldots$, the policy reserve $P$ is compounded with the policy interest rate $r_{\mathrm{P}}(t)$ that depends on the type of guarantee (point-to-point vs. cliquet-style interest rate guarantee) and the type of surplus distribution provided by the insurer. Thus, the development of the policy can in general be described by

$$
P(t)=P(t-1) \cdot\left(1+r_{\mathrm{P}}(t)\right)=P_{0} \cdot \prod_{i=1}^{t}\left(1+r_{\mathrm{P}}(i)\right), t=1,2, \ldots
$$

Depending on the performance of the insurer's asset base, the customer receives the accumulated book value $P(T)$ of the contract at maturity $T$, and, for some contract designs, a terminal bonus $S(T)$. Hence, the payoff $L(T)$ to the policyholder is

$$
L(T)=P(T)+S(T)=P_{0} \cdot \prod_{t=1}^{T}\left(1+r_{\mathrm{P}}(t)\right)+S(T) .
$$

\footnotetext{
${ }^{27}$ Let $\left(W_{t}\right), 0 \leq t \leq T$, be a standard Brownian motion on a probability space $(\Omega, \mathcal{F}, \mathbb{P})$ and $\left(\mathcal{F}_{t}\right), 0 \leq$ $t \leq T$, be the filtration generated by the Brownian motion.

${ }^{28}$ For details see, e. g., Björk (2004). 
The exact form of the terminal bonus $S(T)$ and the policy interest rate $r_{\mathrm{P}}(t)$ depends on the contract specifications, with one example being provided below. The amount of surplus credited to the policy reserves (represented by $r_{\mathrm{P}}(t)$ ) as well as the terminal bonus payment typically depends on the insurance company's financial situation and thus on the development of the insurer's asset portfolio, respectively.

\section{A1.3 Fair contracts}

We determine fair contracts using risk-neutral valuation, such that

$$
V_{0}(L(T))=e^{-r T} \mathbb{E}^{\mathbb{Q}}(L(T)),
$$

where $\mathbb{E}^{\mathbb{Q}}(\cdot)$ denotes the expectation under the risk-neutral martingale measure ${ }^{29} \mathbb{Q}$. A contract is considered fair if the time zero market value $V_{0}(\cdot)$ of the final payoff $L(T)$ under the risk-neutral measure $\mathbb{Q}$ is equal to the up-front premium $P_{0}$ paid by the policyholder, ${ }^{30}$

$$
P_{0}=V_{0}(L(T))=e^{-r T} \mathbb{E}^{\mathbb{Q}}(L(T)) .
$$

This equation can be used to find parameter combinations of fair contracts. Models that do not allow for explicit analytical expressions can be analyzed using simulation techniques. $^{31}$

\section{A1.4 Example: Point-to-point guarantee}

In the case of a point-to-point guarantee, the single up-front premium $P_{0}$ is compounded with the guaranteed interest rate $g$. The policy interest rate is thus given by $r_{\mathrm{P}}(t)=g$, such that at expiration of the contract, the guaranteed payment is

$$
P(T)=P_{0} \cdot \prod_{i=1}^{T}(1+g)=P_{0} \cdot(1+g)^{T} .
$$

Additionally, the customer receives a fraction $\delta$ of the terminal surplus, i. e., if $A(T)-$ $L(T)>0$. Hence, the final payoff $L(T)$ (without accounting for the limited liability of equityholders) can be summarized by

$$
L(T)=P(T)+S(T)=P_{0} \cdot \prod_{i=1}^{T}(1+g)+\delta \cdot \max (A(T)-P(T), 0) .
$$

Thus, the payoff can be decomposed into two parts: the first term is a bond with a fixed payoff, whereas the second term is the payoff of a European call option on $A(T)$ with (stochastic) strike price $P(T)$. The closed-form solution for the market value $V_{0}(L(T))$ of the payoff using European option pricing theory is

$$
V_{0}(L(T))=e^{-r T} \mathbb{E}^{\mathbb{Q}}(L(T))=e^{-r T} \cdot P(T)+\delta \cdot\left(A_{0} \cdot \Phi\left(d_{1}\right)-P(T) \cdot e^{-r T} \cdot \Phi\left(d_{2}\right)\right)
$$

\footnotetext{
${ }^{29}$ For details concerning risk-neutral valuation, see, e. g., Björk (2004).

${ }^{30}$ Note that this equation does not consider the limited liability of equityholders. For an example, see, e. g., Grosen and Jørgensen (2002).

${ }^{31}$ For Monte Carlo simulation, see, e. g., Glasserman (2004).
} 
with

$$
d_{1}=\frac{\ln \left(A_{0} / P(T)\right)+\left(r+\sigma^{2} / 2\right) \cdot T}{\sigma \cdot \sqrt{T}} \text { and } \quad d_{2}=d_{1}-\sigma \cdot \sqrt{T} .
$$

Further types of interest rate guarantees are presented and examined in, e. g., Gatzert and Kling (2007).

\section{References}

Albizzati, M.-O., Geman, H.: Interest rate risk management and valuation of the surrender option in life insurance policies. J. Risk Insur. 61(4), 616-637 (1994)

American Council of Life Insurers: 2007 Life Insurers Fact Book. Available at http://www.acli.org. Accessed 4 December 2008. (2007)

Babbel, D.F., Merrill, C.: Economic valuation models for insurers. N. Am. Actuarial J. 2(3), 1-17 (1998)

Bacinello, A.R.: Fair pricing of life insurance participating policies with a minimum interest rate guarantee. ASTIN Bull. 31(2), 275-297 (2001)

Bacinello, A.R.: Pricing guaranteed life insurance participating policies with annual premiums and surrender option. N. Am. Actuarial J. 7(3), 1-17 (2003a)

Bacinello, A.R.: Fair valuation of a guaranteed life insurance participating contract embedding a surrender option. J. Risk Insur. 70(3), 461-487 (2003b)

Ballotta, L., Haberman, S., Wang, N.: Guarantees in with-profit and unitized with-profit life insurance contracts: Fair valuation problem in presence of the default option. J. Risk Insur. 73(1), 97-121 (2006)

Baur, P., Enz, R.: Solvency II: An integrated risk approach for European insurers. Swiss Re Sigma 4 (2006)

Björk, T.: Arbitrage Theory in Continuous Time. Oxford University Press, New York (2004)

Black, F., Scholes, M.: The pricing of options and corporate liabilities. J. Polit. Econ. 81(3), 637-654 (1973)

Bowers Jr., N.L., Gerber, H.U., Hickman, J.C., Jones, D.A., Nesbitt, C.J.: Actuarial Mathematics. The Society of Actuaries, Illinois (1997)

Boyle, P.P., Hardy, M.R.: Guaranteed annuity options. ASTIN Bull. 33(2), 125-152 (2003)

Boyle, P.P., Schwartz, E.S.: Equilibrium prices of guarantees under equity-linked contracts. J. Risk Insur. 44(4), 639-660 (1977)

Brennan, M.J., Schwartz, E.S.: The pricing of equity-linked life insurance policies with an asset value guarantee. J. Financ. Econ. 3(3), 195-213 (1976)

Briys, E., de Varenne, F.: On the risk of insurance liabilities: Debunking some common pitfalls. J. Risk Insur. 64(4), 673-694 (1997)

Bundesamt für Privatversicherungen: Swiss Solvency Test: Preliminary Analysis Field Test. Available at http://www.bpv.admin.ch. Accessed 4 December 2008. (2005)

Carson, J.M.: Backdating of life insurance contracts: An examination. J. I. R. 13(2), 185-200 (1994)

Carson, J.M., Ostaszewski, K.: The actuarial value of life insurance backdating. J. Actuar. Pract. 11(1), $63-77(2004)$

Cox, J.C., Ross, S.A., Rubinstein, M.: Option Pricing: A simplified approach. J. Financ. Econ. 7(3), 229-263 (1979)

Cummins, J.D., Miltersen, K.R., Persson, S.-A.: International comparison of interest rate guarantees in life insurance. Conference Proceedings ASTIN 2004 (2004)

Dillmann, T.: Modelle zur Bewertung von Optionen in Lebensversicherungsverträgen. Ifa-Verlag, Ulm (2002)

Dillmann, T., Ruß, J.: Implicit options in life insurance contracts: Part 2 - The case of flexible expiration option in endowment contracts. Blätter DGVM 25(2), 225-235 (2001)

Doherty, N.A., Singer, H.J.: The benefits of a secondary market for life insurance policies. Working Paper. Wharton Financial Institutions Center, Philadelphia (2002)

Eling, M., Schmeiser, H., Schmit, J.T.: The Solvency II process: Overview and critical analysis. Risk Manage. Insur. Rev. 10(1), 69-85 (2007) 
Enz, R.: World insurance in 2005: Moderate premium growth, attractive profitability. Swiss Re Sigma 5 (2006)

European Insurance and Reinsurance Federation CEA: The European life insurance market in 2004. CEA Eco, 22. Available at http://www.cea.assur.org. Accessed 4 December 2008. (2006)

FitchRatings: Solvency II - What is happening? Europe Special Report (2005)

Gatzert, N., Kling, A.: Analysis of participating life insurance contracts: A unification approach. J. Risk Insur. 74(3), 547-570 (2007)

Gatzert, N., Hoermann, H., Schmeiser, H.: The impact of the secondary market on life insurers' surrender profits. Working paper on risk management and insurance. University of St. Gallen (2008)

Gatzert, N., Schmeiser, H.: Assessing the risk potential of premium payment options in participating life insurance contracts. J. Risk Insur. 75(3), 691-712 (2008)

Glasserman, P.: Monte Carlo Methods in Financial Engineering. Springer, New York (2004)

Grosen, A., Jørgensen, P.L.: Valuation of early exercisable interest rate guarantees. J. Risk Insur. 64(3), 481-503 (1997)

Grosen, A., Jørgensen, P.L.: Fair valuation of life insurance liabilities: The impact of interest rate guarantees, surrender options, and bonus policies. Insur. Math. Econ. 26(1), 37-57 (2000)

Grosen, A., Jørgensen, P.L.: Life insurance liabilities at market value: An analysis of insolvency risk, bonus policy, and regulatory intervention rules in a barrier option framework. J. Risk Insur. 69(1), 63-91 (2002)

Guillén, M., Jørgensen, P.L., Nielsen, J.P.: Return smoothing mechanisms in life and pension insurance: Path-dependent contingent claims. Insur. Math. Econ. 38(2), 229-252 (2006)

Haberman, S., Ballotta, L.: Valuation of guaranteed annuity conversion options. Insur. Math. Econ. 33(1), 87-108 (2003)

Haberman, S., Ballotta, L., Wang, N.: Modelling and valuation of guarantees in with-profit and unitised with-profit life insurance contracts. Actuarial Research Paper No. 146. Department of Actuarial Science and Statistics, Cass Business School London (2003)

Hansen, M., Miltersen, K.R.: Minimum rate of return guarantees: The Danish case. Scand. Actuar. J. 2002(4), 280-318 (2002)

Held, W.C.: Optionen in Lebensversicherungsverträgen. Ifa-Verlag, Ulm (1999)

Helfenstein, R., Barnshaw, M.: Unit-linked life insurance in Western Europe: Regaining momentum? Swiss Re Sigma 3 (2003)

Herr, H.-O.: Implizite Finanzoptionen: Abschlussbericht zur Methodik der Bewertung von impliziten Finanzoptionen in Lebensversicherungsprodukten. Versicherungswirtschaft, Karlsruhe (2004)

IASB: Discussion paper fair value measurements, Part 1: Invitation to comment and relevant IFRS guidance. Available at: http://www.iasb.org. Accessed 4 December 2008. (2006)

Jensen, B., Jørgensen, P.L., Grosen, A.: A finite difference approach to the valuation of path dependent life insurance liabilities. Geneva Pap. Risk Insur. Theory 26(3), 57-84 (2001)

Jørgensen, P.L.: On accounting standards and fair valuation of life insurance and pension liabilities. Scand. Actuar. J. 2004(5), 372-394 (2004)

Kling, A., Richter, A., Ruß, J.: The interaction of guarantees, surplus distribution, and asset allocation in with profit life insurance policies. Insur. Math. Econ. 40, 164-178 (2007)

Linnemann, P.: An actuarial analysis of participating life insurance. Scand. Actuar. J. 2003(2), 153-176 (2003)

Linnemann, P.: Valuation of participating life insurance liabilities. Scand. Actuar. J. 2004(2), 81-104 (2004)

Merton, R.C.: Theory of rational option pricing. Bell J. Econ. Manage. Sci. 4(1), 41-183 (1973)

Milevsky, M.A., Promislow, S.D.: Mortality derivatives and the option to annuitize. Insur. Math. Econ. 29(3), 299-318 (2001)

Miltersen, K.R., Persson, S.-A.: Guaranteed investment contracts: Distributed and undistributed excess return. Scand. Actuar. J. 2003(4), 257-279 (2003)

O'Brien, C.: The downfall of equitable life in the United Kingdom: The mismatch of strategy and risk management. Risk Manage. Insur. Rev. 9(2), 189-204 (2006)

Steffensen, M.: Intervention options in life insurance. Insur. Math. Econ. 31(1), 71-85 (2002)

Tanskanen, A.J., Lukkarinen, J.: Fair valuation of path-dependent participating life insurance contracts. Insur. Math. Econ. 33(3), 595-609 (2003) 
Trieschmann, J.S., Hoyt, R.E., Sommer D.W.: Risk Management and Insurance, 12th edition. SouthWestern College Pub., Mason (2005)

Wong, C., Barnshaw, M., Bevere, L.: Allfinanz: Trends, Chancen und Herausforderungen. Swiss Re Sigma 5 (2007) 